\title{
Single Resin Bead Kinetics Using Real Time Fluorescence Measurements
}

Puja B. Parikh, Young-Soo Kim, and Young-Tae Chang ${ }^{\circ}$

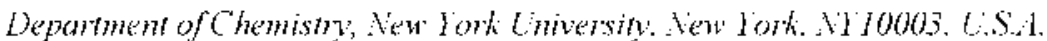 \\ Received Alugust 5. 2002
}

\begin{abstract}
Key Words : Combinatorial library. Real time tluorescence measurement, Single resin bead kinetics, Solid phase labeling reagent
\end{abstract}

Fluorescence techniques have been used widely in chemistry and biology for over a century." With the adicnt of combinatorial solid phase synthesis. a varicty of fluorescence 1echniques for resin beads have been dereloped and adopled for broad applications. which include encoding/decoding." nluorescent molecule binding assays. ${ }^{3}$ and catalylic activily detection." The split-and-pool method. another important technique in combinatorial chemistry. facilitates the synthesis of millions of molecules in a one-bead-one-compound library format: in principle. cacl single bead of resin acts as a separate microreactor. Although conventional screcnings of these split-and-pool libraries have usually been performed as inixtures. a segregation approach of each single resin has been demonstrated recently: avoiding complicated data analysis. " To simplify the liandling of a single resin. the researchers necessarily ulilized a super size bead (a $500 \mu \mathrm{m}$ diancter Rapp PS (polysty renc) bead. aboul 5-fold larger in diameter than an ordinasy synthetic resin) with the aid of bead arraying lools.

The problem will the kinclics of solid phase reaclions is that it demands. in many cascs. if not all. tcdious sample preparation steps including filtering. wasling and transferring. While single resin bead FT-IR specira have becn ulilired successfully to quantify solid plase reaction rates. ${ }^{6}$ no comparable fllorescence kinclics has yel becn demonstrated. Herein we report the first cxample of single resin bead kinctics using comtimuous measurement of fluorescence generation on an actiyated ester resin.

Aclivated esters on solid suppon lave becn developed as concenicm labcling reagents. especially for aminc nuclcoplites. ${ }^{5-9}$ Most of the reponted functionalities. sucl as nitrophenol. N-lyydroxysuccinimide. HOBt (1-lỵdroxybemotriarole) and Kaiscr oxime. lave been attached to a polysty rene solid suppont by a Fricdcl-Craft reaction ${ }^{\text {le }}$ or to a thiol resin by a malcimide linker. limiting the selection of resin compositions. To overcome this limitation. we utilized the well-cslablished amide bond formation to couple telra7uoro-4-lyydroxy benzoic acid with an aminometlyyl resin (1). which has a broad material sclection. creating a novel 1clrafluorophenol resin (2). "] For kinetic studies under various conditions. an csk ironment-insensitive ligh quantum yicld fluorescence moleculc. 4-acclamino-1.8-maphthalimide (3). "was chosen to prepare line acivaled esier resm $(\boldsymbol{A}){ }^{1]}$

"Comesponding Author. Phone: +1-212-998-8491: Fax: +1-212260-7905: e-mail: vt.chang àny y.edu
When reacted with a small amount of bensylanine $(\mathbf{B})$ in various solvents, resin $\mathbf{A}$ gave a pure product $(\boldsymbol{C})$ withoul work-up or purification, and the anount of generated product could be quantified by fluorescence neasurement. Similarly obtained fluorescence data was previously used to calculate the sccond order reaction rate constant of nitrophenol resin. after removal of the resin by filtration followed by a sample dilution.

One important obsenation was that the fluorescence was quenclied almosi completely in the resin-bound molecule. while the released product $\boldsymbol{C}$ showed a bright fluorescence: the fluorescence on the resin was less than $1 \% / n$ of that of product $C$ in solution. Considering the fact that the fluorescence of a dyc with a large Stokes shift was nol selfquenched on the resin bead. ${ }^{12}$ the quencling effect of resin $\mathbf{A}$ may be due to pluysical confinement of the dyes on to a simall resin rather than due to a photochenical quenching. This phenomenon opened up the clance to study an in situ kinctic bclay ior of this resin without any sampling process. which facilitated data collection in a short time. Another improvement was aclicicd by clanging the second order reaction of

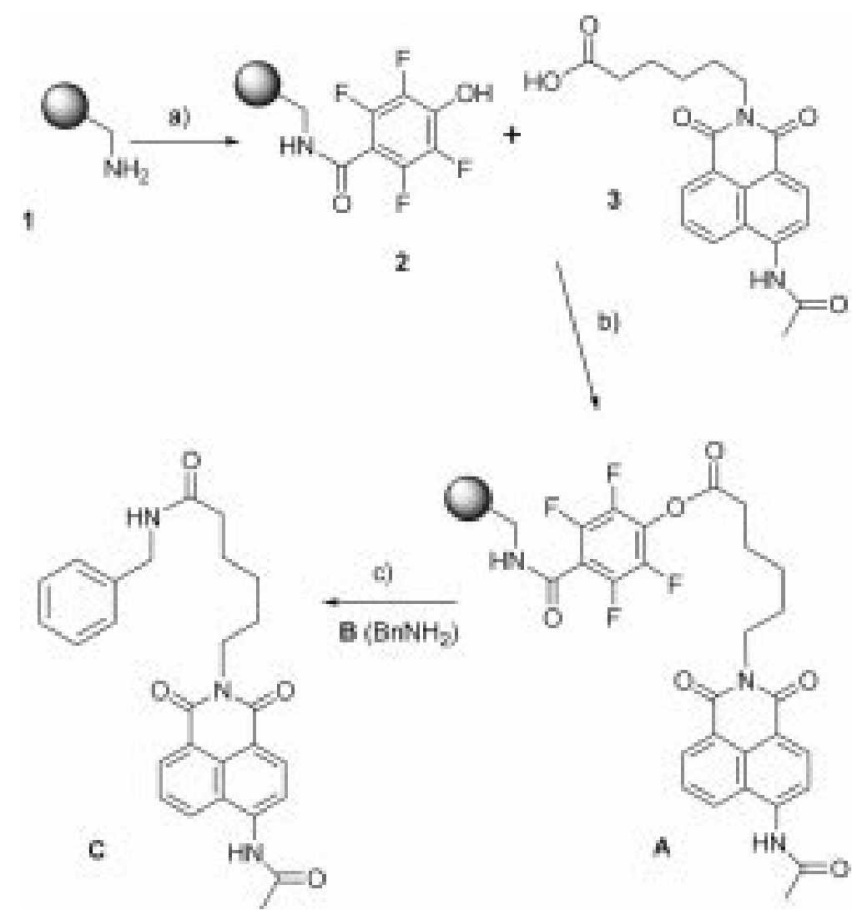

Scheme 1. (a) ketrafluoro-4-hydroxy benzoic acid. DIC. IIOLB, DMl' (b) 3. DIC. DMAP. DMl' (c) B. DMF: 


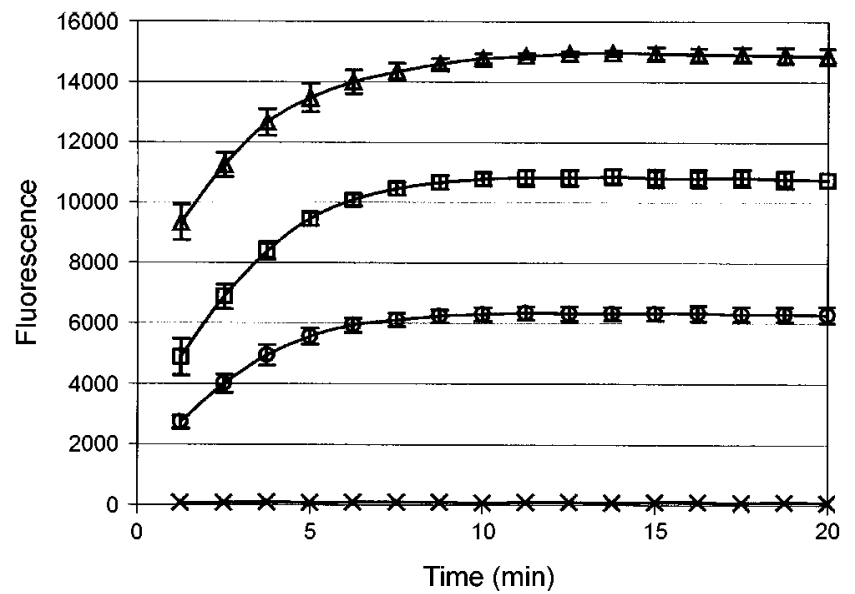

Figure 1. 1'luorescence measurement of LCC PS resin (A) tith

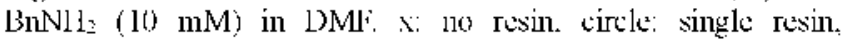
quadrangle: two resins, triangle: three resins. Standard deviation was given for the error bar.

aminolysis into a pseudo-first-order reaction by using an excess of the amine. This conversion has several significant advantages: 1) the kinetic reaction measurement time can be shortened from many hours (or even days) to less than one hour: 2 ) the pseudo-first-order reaction rate constant $\left(\mathrm{k}^{*}\right)$ can be obtained from the slope of a linear relationship of $\ln [1 / 1-$ relative conversion)] $w$. time: ${ }^{13}$ 3) although the kinetic starting point was not exactly synchronized due to an experimental deviation. it does not affect the calculation of $\mathrm{k}:$ and 4$)$ since the relative conversion. $[\mathbf{C}] /\left[\mathbf{A}_{0}\right]$. instead of the absolute amount of $\mathbf{A}$ consumed in the reaction profile. is utilized in the rate constant determination. measuring the initial amount of resin is not required. Normally one is obliged to use at least multi ing resins for each kinetic study ${ }^{-}$ However, the last advantage allowed us to reduce the scale of the reaction. even down to a single resin bead.

To miniaturize the reaction. we tested a $384-w$ well plate format with $50 \mu \mathrm{L}$ reaction volumes containing benzylamine (10 $\mathrm{mM}$ final concentration). and recorded the fluorescence change using a plate reader $\left(\lambda_{\mathrm{rx}}=370 \mathrm{~nm}, \lambda_{\mathrm{col}}=455 \mathrm{~mm}\right){ }^{1-1}$ To make sure we were measuring a single resin bead's behavior. a homogeneous size resin (186 $\mu \mathrm{m}$. LCC Reactospheres PS aminomethyl resin) was utilized. When diluted enough. zero to several resin beads could be transferred to the plate wells by pipetting and the fluorescence generation was recorded as a function of time as shown in Figure 1. While almost half of the wells showed no fluorescence. several wells showed a clear quantization of fluorescence generated from one. two. or three resin beads: there was no fluorescence curve intermediate between one and zero resin wells. A standard curve constructed with product $\mathbf{C}$ (1-100) $\mu \mathrm{M}$ in $50 \mu \mathrm{L}$ DMF solution) indicated that the loading level of each single bead is about $1.1 \mathrm{mmol} / \mathrm{resin}(22 \mu \mathrm{M}$ in $50 \mu \mathrm{L}$ DMSO solution. the loading level of original aminomethyl resin is $2.7 \mathrm{mmol} / \mathrm{resin})^{1.5}$ Furthermore. the pseudo-firstorder reaction rate constant $\mathrm{k}^{\star}$ was also calculated from a linear plot of the data. finally giving the second order reaction constant $\mathrm{k}$ as $+6.9( \pm 5.5) \mathrm{M}^{-1} \mathrm{~min}^{-1}$. As expected. the resin number in each well did not affect the kinetic results.

In conclusion. we have successfully demonstrated the first single resin bead kinetics based on continuous fluoresecence measurement. This hightlurouput kinetics approach will be useful to study the statistics of single bead belaviors and loading level measurements in a short period of time. The novel fluorescence labeling reagent containing tetrafluorophenol in various solid support materials will be used as key reagents to generate useful amide libraries and to label various amine-containing biological probes.

\section{References}

1. Apphed Flworescence in Chemistry Biology and Medicine: Rettig. W.. Strehmel. B.. Schrader. S.. Seilert. H.. Eds.: Springer: New York. 1999.

2. (a) Grondahl, I..: Battersbr, B. J.: Bryatt. D.: Trau. M. Langmuir 2000, 16,9709-9715. (b) Battersby: B. I.: Bryant. D.: Meutermans. W.: Matthews, D.: Smythe. M. I.: Trau. M. J. Am. Chem. Soc. 2000. 122. 2138-2139. (c) Egner. B. J.: Rana. S.: Smilh. H.: Bouloc. N.: Frey. J. G.: Broctlesby. W. S.: Bradley. M. (hem. Conmm 1997. 735-736.

3. (a) I.cwis. I. C.: Daunett. S. Anat. Chem 1999. 71, 4.321-4.327. (b) Rao, S. V.: Anderson, K. P.: Bachas. I. G. Bioconngate Chem. $1997,8.94-98$

4. (a) Harris. R. F.: Nation. A. J.: Copeland. G. T.: Miller. S. I. J. . tm. Chem Soc. 2000. 122. 11270-11271. (b) Copeland. (i) 'T.: Miller. S. J. J. in (Them. Soc. 1999. 121.4306-4307.

5. Sternson, S. M.: Jouca, J. B.: Wong. J. C.: Schreiber, S. I.. J. Am. Chem. Soc: 2001. 123, 1740-1747.

6. I.i, W. Yant. B.J. Ong. Chem. 1998. 63. $4092-4097$.

7. Chang. Y. T.: Scluultz. P. G. Bioorg. Wed (Them. Lett 1999. 9. $2479-2482$

8. Masula. S.: Tuddei. M. Org. Lett. 1999. /. 1355-1357.

9. (a) Katoh. M.: Sodeoka. M. Bioong. Hed. Chem. Leth 1999. 9. 881-884. (b) Adamczrk. M.: Fishpaugh. I. R.: Mattingly: P. G Tetwhedron Letl. 1999, fo. $463-466$. (c) Adancrik. M.: Fishpatgh. J. R.: Mattingly. P. G. Bionerg. Wed Chem Itiff. 1999. 9.217-220.

10. (a) Cohen. B. I.: Karoly-Hafeli. H.: P'atchornik. A. J. Org. ('he'th. 1984, 49. 922-924. (b) Scialdone. M. A.: Slues, S. W.: Soper. P.: Ilamuro, Y.: Burns, D. M. J. Org. Chem 1998. 63. $4802-4807$.

11. Walsh. D. P.: Pang. C.: Parikh, P. B.: Kim. Y. S.: Chang. Y. T. $J$. Comb. Chem 2002, t. 204-208.

12. Yan. B.: Martin. 1'. C.: Lee. J. J. Comh. ('he'm. 1999. /. 78-81.

13. Caroll. F. A. Perspectives ow Stuture and hechanism in Organic Chemishn: Brooks Cole: Pacific Grove, 1998: pp.3.32-339.

14. Fach resin (A) was initially suspended in dichloromethanc and approximately $30 \mu \mathrm{t}$. were transferred to each well of a 384 -well plate. After the dichloromethane had completely evaporated. DMF ( $40 \mu \mathrm{L}$ ) was translerred into each resin-containing well and the resin was allowed to swell hor approximately 5 min. Bencylamine ( $10 \mu \mathrm{I}, 50 \mathrm{mM}$ in DMF) was simultancously transterred into each of these wells by a multi-channel pipette and the fluoresence was measured by a tluoresence plate reader (Spectramax GEMINI XS Microplate Reader. Molecular Devices). The excitation and emission wavelengths were $370 \mathrm{~nm}$ and 455 $n \mathrm{n}$ respectively: and the temperature was controlled at 25 "C. Fach data point was reorded tor intervals in the range of 20-120 seconds, and plate-slaking timc was set at 5 scconds initially and 3 seconds betwecn data readouts to ensure solution homogeneits:

15. Calculated loading level by the product company: personal communication will Dr. Willi Glellig of LCC Encineering \& Trading GmbH (http: www:clemsupply.ch). 